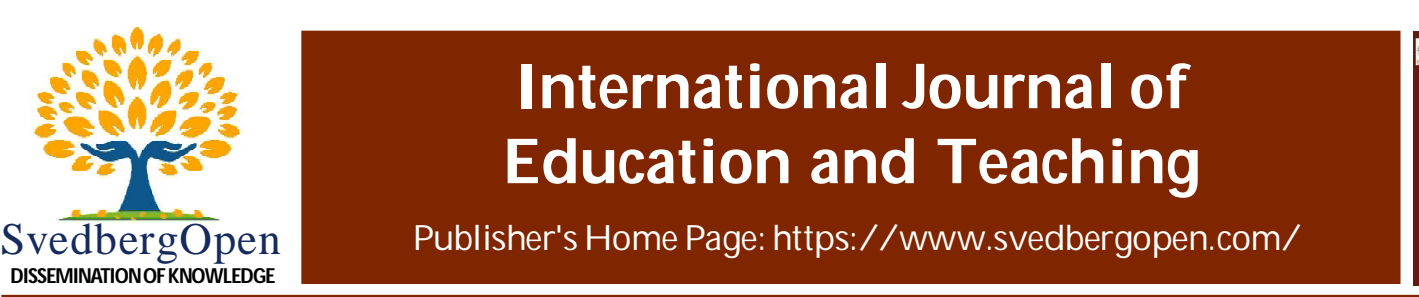

Short Communication

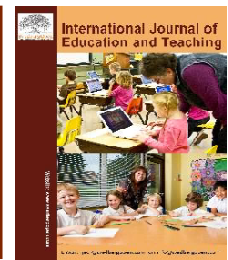

\title{
Assessment and feedback strategies that foster students' engagement in the language classroom
}

\author{
Salwa Mohamed ${ }^{1 *}$ and Fiona Long ${ }^{2}$ \\ ${ }^{1}$ Manchester Metropolitan University, Manchester M15 6BH, United Kingdom. E-mail: s.a.mohamed@mmu.ac.uk \\ ${ }^{2}$ Manchester Metropolitan University, Manchester M15 6BH, United Kingdom. E-mail: f.long@mmu.ac.uk
}

Volume 1, Issue 1, March 2021

Received : 16 November 2020

Accepted : 20 January 2021

Published : 05 March 2021

doi: 10.51483/IJEDT.1.1.2021.13-18

\begin{abstract}
Assessment is said to be the most important component in students' learning experience in higher education (Orr et al., 2012) and the main motivation for learning (Boud, 1995; Race, 2014). Changing methods of assessment has the power to improve both teaching (Elton and Johnston, 2002; Gibbs and Simpson, 2004-05) and learning (Brown et al., 1997; Gibbs, 1999). Yet, assessment and feedback are usually found to be the least satisfactory aspects for students in higher education (Orr et al., 2012; Race, 2014). In addition, teachers are less responsive to changing their assessment methods than they are to improving and varying their teaching (Orr et al., 2012; Rust, 2002); they also know little about how their students respond to assessment (Gibbs and Simpson, 2004). This paper reflects on useful strategies that can enhance both assessment and feedback in the language classroom and potentially in other teaching subjects.

Keywords: Assessment, Assessment for learning, Feedback, Student engagement, Language classroom

() 2021 International Journal of Education and Teaching. This is an open access article under the CC BY license (https://creativecommons.org/licenses/by/4.0/), which permits unrestricted use, distribution, and reproduction in any medium, provided you give appropriate credit to the original author(s) and the source, provide a link to the Creative Commons license, and indicate if changes were made.
\end{abstract}

\section{Introduction}

More recently, there has been more emphasis on formative assessment or assessment for learning. The difference between formative and summative evaluation is that the former is used to provide sufficient feedback to improve students' learning before reaching the grading stage with the summative evaluation (Boud, 1995). However, there is evidence that students do not care much about doing assignments that do not count towards their final mark (Elton and Johnston, 2002; Gibbs and Simpson, 2004-05; Race, 2014; Rust, 2002), and when they do, they do not care about reading the feedback or even collecting the work in some cases (Gibbs and Simpson, 2004-05). This, as Boud (1995, p. 2) states, is because the concern about summative assessment tends to "swamp the more modest endeavors of formative assessment." This paper provides some useful strategies for the design of assessment and feedback to enhance students' engagement in the language classroom and promote assessment for learning.

\section{The design of assessment tasks}

This section focuses on four strategies that should be maintained in the design of assessment tasks to foster student's maximum engagement with learning activities.

\footnotetext{
* Corresponding author: Salwa Mohamed, Manchester Metropolitan University, Manchester M15 6BH, United Kingdom.

E-mail: s.a.mohamed@mmu.ac.uk
} 


\subsection{The use of frequent assignments}

Assessment methods have been found to play a crucial role in directing students' learning and how much time they spend on studying (Brown et al., 1997; Gibbs, 1999; Gibbs and Simpson, 2004-05; Rust, 2002). There has been a negative backwash effect for the emphasis on and widespread use of summative examinations which encourage superficial learning in the sense that students focus on the content they think will be covered in final examinations regardless of what has been taught in class (Biggs, 2003; Brown et al., 1997; Elton and Johnston, 2002; Race, 2014). This leads to rote learning and to bunching learning just before exams (Gibbs and Simpson, 2004-05). This is actually more risky and detrimental with foreign language learners as the object of study — the language — is both an end and a means to learning. In effect, this means that language learners need to engage with the language regularly in order to progress in their knowledge and achieve well on their assessments. This requires assessment methods that encourage continuous and regular learning and use of the target language throughout the year. Currently, there has been increasing calls for using formative assessment in the form of frequent assignments as a result of the increasing challenges such as the increasing number of students, the concomitant resource constraints and teachers' workload. Bloxham and Boyd (2007, p. 184) call for reducing examinations in favor of "continuous forms of assessment or regular sub-tasks that might build up to a final summative assessment .... These continuous methods can provide important formative assessment and encourage engagement with the module". This can be an advantage when learning is taking place in an online environment where it can be difficult to engage learners, especially those who are new to this mode of study.

The use of frequent assessment tasks does not only generate increased study time, it also helps to capture students' time and effort and distribute them more evenly and effectively across the course (Bloxham and Boyd, 2007; Gibbs and Simpson, 2004-05). This helps in diagnosing any learning difficulties early in the course and increases academic engagement and achievement. It also links to the quality of learning; exams encourage students to focus only on the topics they think will be covered in the assessment (Gibbs and Simpson, 2004-05). A study by Chansarkar and Raut Roy (1987 cited in Gibbs and Simpson, 2004-05, p. 6) reports that the combination of coursework assignments and examinations yields up to $12 \%$ better average mark rates than examinations only.

Moreover, the use of frequent assessment helps to improve attendance (Bloxham and Boyd, 2007) and retention (Orr et al., 2012; Yorke, 2001). This is particularly important when classes are being held online. Engagement and retention are constant concerns in higher education and even more so in the online learning world. Confidence building (Black and Wiliam, 1998) was mentioned as another benefit. Race (2014) links continuous assessment and students' wanting to learn; it gives students an incentive to learn due to the fact that they gain marks (which is their main concern) throughout the year and so reduces fear of and preoccupation with final exams. This gives room for focusing on learning.

\subsection{The use of varied tasks}

Race (2014, p. 96) states that "the 'want' to learn is damaged by the mere thought of looming exams." The use of varied tasks and providing students with an element of choice has been shown to encourage intrinsic motivation (Bloxham and Boyd, 2007; Rust, 2002). The use of varied tasks prepares students for the summative end of year exams while at the same time helping them accumulate marks towards their final grade. This reduces the burden of final exams, and increases students' intrinsic motivation, which allows them to learn for the sake of learning (Race, 2014). Elton and Johnston (2002, p. 17) agree that "... once the summative assessment needs have been met through appropriate formative assessment, students are willing to consider higher aims such as learning for its own sake."

Using varied assessment tasks also promotes equity and wide participation (Bloxham and Boyd, 2007). Since there is no single assessment method that suits every student, the use of a mix of assessment methods is fairer in the sense that no students are particularly advantaged or disadvantaged by the use of the same assessment method (e.g., unseen exams) over and over again (Race, 2014). Gibbs and Simpson (2004-05) make the point that students believe continuous assessments are fairer than examinations as they measure a wider range of abilities, and help them keep up with their work.

\subsection{The use of real life/authentic tasks}

There is an increasing demand on authentic assessments that has real life application. Race (2014) recommends the use of assignments that are wider in scope, practical and relevant to real world tasks. The style of studying that accompanies such assignments generates deep learning with "more emphasis on thinking and ...... sophisticated conceptions of learning" (Gibbs and Simpson 2004-05, p. 7). In language teaching, this can take be achieved in different ways; for example, assessments can move from the classical categorization of the four language skills (listening, speaking, reading and writing) to more integrative modes of reception, production, interaction and mediation advocated by the Common European Framework of Reference for Languages (CEFR) (CoE, 2001). Testing a variety of skills in an integrated way 
mirrors real life usage. Another way of improving the authenticity of language assessments is the use of cohesive assignments (Trumbore, 2014). Trumbore's research into MOOCs gives examples of project work where smaller, cohesive assignments led to final projects, which had applications both on the course and in the real world. Besides, the tasks within the assessment gave students more opportunities to engage deeply with the course and to learn knowledge and skills that could be used in the future outside the classroom, potentially in employment contexts. Such opportunities included giving and receiving peer feedback, peer grading, which also taught critical evaluation through students' use of a specific rubric and teamwork (which was highly valued among students) (Trumbore, 2014). This way, the use of real life/authentic assessments broadens the scope and potential of the assessment to become a tool for learning than just the achievement of a grade.

In addition to that, the use of real life tasks allows for the measurement of broader graduate attributes, process outcomes and higher order skills, e.g., self and peer evaluation, critical thinking and problem solving. Such higher order skills cannot be measured in traditional examinations due to the time limitations and stress that accompany such assessments (Bloxham and Boyd, 2007; Elton and Johnston, 2002).

\subsection{The use of relevant and appropriate range of learning aspects and skills}

A good assessment plan directs students to focus their learning on the most important and needed learning aspects (e.g., vocab, grammar) and skills (e.g., writing, listening, speaking) relevant to a language course. This increases the assessment's consequential validity (Boud, 1995) in that it helps students to organize their work patterns and keep up with their work, studying what is intended for them to learn. This contributes to deep approaches to learning and increases their achievement (Gibbs and Simpson, 2004-05). Biggs' (1996 and 2003) principle of constructive alignment states that decisions about assessment types and learning activities should be guided by a course's learning outcomes. The skills taught and the modes of assessment used should enable the learners to demonstrate that they can (to a greater or lesser extent) meet the learning outcomes of the course. Nerantzi and Chatzidamianos (2020, p. 468) propose that the assessment plan includes regular activities for which "students receive formative feedback without the need for additional hours dedicated specifically to assessment preparation". This approach lends itself to a portfolio approach. Tasks can be adapted to suit both online and face-to-face learning contexts and where possible, give the students the flexibility to achieve the relevant learning outcomes through researching topics of their own choice. This way, the learning aspects and skills taught on the course facilitate a broader and perhaps more personalized range of exploration than may have been anticipated by the students.

\section{The design of feedback}

This section, in turn, focuses on four strategies that should be observed/maintained in the design of feedback to further foster student's maximum engagement with learning activities.

\subsection{The timing and quality of feedback}

An effective assessment plan provides students with early feedback in the course; this gives them the opportunity to work on improving their learning in terms of quality and study time (Gibbs and Simpson, 2004-05; Race, 2014), which links to academic engagement and deep learning discussed above. Summative assessments, especially in the form of final exams do not allow for that; in such exams, the feedback is often too late for students to benefit from or act upon. Even with earlier summative assessments, students are usually more concerned about the grade and might not attend to the feedback. Using continuous assessment or frequent assignments as discussed above means that feedback can be given between tests, focusing on what has been done well and areas which could be improved before the next assessment.

The quality of the feedback is also important for learning. Gibbs and Simpson (2004-05) recommend regular and detailed feedback on small and specific chunks of content. This provides students with the support needed for academic integration into higher education, particularly so with struggling and disadvantaged students (Black and William, 1998) which improves retention (Race, 2014; Yorke, 2001).

The assessment plan should link marking and feedback exercises to the module's marking criteria and, where relevant, to model answers (prepared by the teacher) as these work as referents for students in judging their own and others' work (Gibbs, 1999). According to Gibbs and Simpson (2004-05) and O'Donovan et al. (2004), students need to understand marking criteria and standards to improve their performance; this is best done through engaging students in self and peer assessment where they apply marking criteria and use model answers (see next point). This helps students internalize standards and establish and meet the expectations of good performance (Gibbs and Simpson, 2004-05; Gibbs, 2015; Jessop and El Hakim, 2010). 


\subsection{Varying modes of feedback}

One of the most common methods of giving feedback on students' work is written feedback. It is more sustainable than other forms of feedback; however, it is time consuming (Ryan et al., 2019). An alternative to that, as Ryan et al. suggest, is the use of rubrics and mark sheets, which allow for more information even though they lack personalization. Audio feedback is another mode that allows for more detailed feedback than written feedback (Martin et al., 2018; Ryan et al., 2019). Ice et al. (2007) used audio feedback along with text-based feedback to personalize their communication with students in online teaching and create a sense of community. Besides, students were more inclined to act upon audio feedback than they were with written feedback. (Ice et al., 2007). Face-to-face feedback is important in creating dialogue between the teacher and student; it aids understanding and allows students to ask for further clarification. However, this can be time consuming (Ryan et al., 2019). Group feedback is more economic in terms of time; Oswald and Rhoten (2014) found that group feedback improved incentive and increased score. In general, group feedback is particularly important to encourage group learning and guide teams to achieve their goal (London and Sessa, 2006).

Ryan et al. (2019) recommend the use of multiple modes; in their study they found that students who received different forms of feedback found it thorough, usable and personalized, especially when it included digital recording.

Unlike the above forms of reactive feedback, Dennen et al. (2007) highlight the importance of proactive feedback. This involves providing clear instructor expectations, e.g., the quality and quantity of student contribution, examples of completed assignments or models of expected discussion behavior and proactive response to learner needs. In online learning, in particular, students expect to receive enough information about assignments, marking criteria and the course in general even before it starts. Such methods are indicators of instructor presence, which is a crucial factor in students' engagement and success in online courses (Martin et al., 2018).

\subsection{Involving students with feedback}

"[I]nviting students into the marking process can mean that assessment broadens out from merely the assessment of learning to become an effective learning tool in its own right, facilitating assessment for learning" (O'Donovan et al., 2004, p. 332). Thus, an effective assessment plan promotes self and peer feedback to maximize students' engagement with marking criteria. This, as has been shown in the previous point, enhances students' internalizing of standards and criteria, increases their awareness of how their performance is assessed and, consequently, improves academic engagement and achievement (Bloxham and Boyd 2007; Orr et al., 2012, Race, 2014; Rust, 2001). This, in turn, helps students become autonomous learners capable of reflecting on and reviewing their learning strategies and goals as well as learning to evaluate critically, which not only contributes to academic progression (Elwood and Klenowski, 2002; Gibbs and Simpson, 2004-05; O'Donovan et al., 2004), but are crucial skills for employment and lifelong learning (Orr et al., 2012; Trumbore, 2014).

Literature shows that students enjoy self and peer marking exercises as they help them "by becoming more critical and working in more structured ways" (O'Donovan et al., 2004, p. 332). It was also found that such exercises help them improve their mark by a grade classification (Jessop and El Hakim, 2010).

From a practical point of view, the involvement of students in marking facilitates the implementation of formative assessment in that it does not 'generate' extra marking load on teachers (Gibbs and Simpson, 2004-05; Race, 2014). This is a particularly important consideration for teachers working in online learning environments where the workload is usually perceived as heavier than in a traditional classroom (Tynan et al., 2015). It also places students' views into focus, which increases satisfaction, pass rates and retention. This, consequently, reduces the costs of later re-sits, complaints and appeals (Orr et al., 2012).

\subsection{Encouraging students to act upon feedback}

For feedback to lead to learning, students need to actively engage with it (Gibbs, 1999; Rust, 2002). To make sure that feedback, whether teacher-led or student-led, is attended to and acted upon, a good assessment plan promotes reflection and self-evaluation. Having students to reflect on the feedback they receive on their work helps them to engage with the feedback and make sense of it (Jessop and El Hakim, 2010). Gibbs and Simpson (2004-05) agree that this enhances students' awareness of any gaps in their learning as manifested in the feedback and leads them to improve their learning style. Testing through a portfolio of assessments enhances opportunities for both reflection and development. Students can become involved in a cycle of feedback and improvement which enables them to refine their skills during a course as a result of noticing what has brought success in previous elements of assessment. This can be very motivating. Equally, reflection between assessments gives learners the option of exploring strategies to improve their skills. 
A good assessment strategy also provides opportunities for students to discuss the tutor's or their peers' feedback. Written criteria make sense and become internalized only through student-student and teacher-student interaction, discussions of strengths and weaknesses and making judgments about the quality and standard of different assignments (Gibbs, 2015; Jessop and El Hakim, 2010). This increases consequential validity (Boud, 1995) and fosters collaboration rather than competition among learners (Black and Wiliam, 1998). As Elton and Johnston (2002, p. 17) put it, "if students are given a real stake in their own learning, they will learn better, with more enthusiasm and with less of an eye on their summative assessment when such assessment is needed".

\section{Challenges and implications}

Some reservations have been raised about the use of formative assessment as summative assessment in the same time, e.g., the possibility of plagiarism, summative aspects taking over the formative ones. These may be counteracted by adding an element of reflection and self-evaluation (meta-cognitive work) to the assessment. A further criticism to short frequent assessments is that "[L]ots of small assignments may limit the chance for reflection and make them rather narrow in scope and undemanding in nature” (Bloxham and Boyd's 2007, p. 184). This might not be an issue for language learning since the focus is usually more on skills and interaction than on content, and even when focusing on content it is more on language elements rather than on the accumulation of information as might be the case in other content subjects. In other words, narrow-scope tasks are relevant and appropriate learning tasks for the discipline of language learning, especially at lower levels. Moreover, involving students in marking, using marking criteria and model answers and subsequent discussions of teacher's and peer's feedback should help in extending the benefit of these tasks.

A common concern about the use of frequent assessments is the subsequent marking volume for staff. As mentioned above, this can be mitigated by involving students in self and peer marking. A last word of caution is that some students might be skeptical about new types of assessment and consequently might resist or lack motivation for them (Bloxham and Boyd, 2007). Therefore, new types of assessment need to be discussed on a departmental level with colleagues and senior members. It is also crucial to prepare students for the change by clarifying the rationale, relevance and usefulness of the new assessment strategy.

\section{References}

Biggs, John (1996). Enhancing teaching through constructive alignment. Higher Education. 32, 347-364.

Biggs, John (2003) Aligning teaching and assessment to curriculum objectives. LTSN Generic Centre. https:// www.heacademy.ac.uk/system/files/biggs-aligning-teaching-and-assessment.pdf

Black, Paul and Wiliam, Dylan (1998). Assessment and classroom learning. Assessment in Education: Principles, Policy and Practice. 5(1), 7-74.

Bloxham, Sue and Boyd, Pete (2007). Developing effective assessment in higher education: A practical guide. Open University Press.

Boud, David (1995). Assessment and learning: contradictory or complementary. in Knight, P. (ed.) Assessment for Learning in Higher Education. London: 35-48.

Brown, George; Bull, Joana and Pendlebury, Malcolm (1997). Assessing Student Learning in Higher Education. London: Routledge.

Council of Europe (CoE) (2001). Common European Framework of Reference for Languages: learning, teaching, assessment. Cambridge: Cambridge University Press.

Dennen, Vanessa P., Darabi, Aubteen A. and Smith, Linda J (2007). Instructor-learner interaction in online courses: The relative perceived importance of particular instructor actions on performance and satisfaction. Distance Education. 28(1), 65-79.

Elton, Lewis and Johnston, Brenda (2002) Assessment in universities: a critical review of research. LTSN Generic centre. https://eprints.soton.ac.uk/59244/1/59244.pdf

Elwood, Jannette and Klenowski, Val (2002). "Creating communities of shared practice: the challenges of assessment use in learning and teaching". Assessment and Evaluation in Higher Education, 27(3), 243-256.

Gibbs, Graham (1999). Using assessment strategically to change the way students learn. in Brown, Sally and Glasner, Angela (eds). Assessment Matters in Higher Education: choosing and using diverse approaches. Open University Press. 
Gibbs, Graham and Simpson, Claire (2004-05). Conditions under which assessment supports students' learning. Learning and Teaching in Higher Education. (1), 3-31.

Gibbs, Graham (2015). Making feedback on assignments effective: principles and guidance for tutors. TESTA. http:// testa.ac.uk/index.php/resources/best-practice-guides/category/7-best-practice-guides

Ice, Philip; Curtis, Reagan; Phillips, Perry and Wells, John (2007). Using asynchronous audio feedback to enhance teaching presence and students' sense of community. Journal of Asynchronous Learning Networks. 11(2), 3-25.

Jessop, Tansy and El Hakim, Yaz (2010). Nine ideas for feedback week: an evidence-based guide. TESTA. http:// testa.ac.uk/index.php/resources/best-practice-guides/category/7-best-practice-guides

London, Manuel and Sessa, Valerie I. (2006). Group feedback for continuous learning. Human Resource Development Review. 5(3), 303-329.

Martin, Florence; Wang, Chuang and Sadaf, Ayesha (2018). Student perception of helpfulness of facilitation strategies that enhance instructor presence, connectedness, engagement and learning in online courses. The Internet and Higher Education, 37, 52-65.

Nerantzi, Chrissi and Chatzidamianos, Gerasimos (2020). Moving to block teaching during the COVID-19 pandemic. International Journal of Management and Applied Research. 7(4), 483-495.

O’Donovan, Berry; Price, Margaret and Rust, Chris (2004). Know what I mean? Enhancing student understanding of assessment standards and criteria. Teaching in Higher Education. 9(3), 325-335.

Orr, Susan; Ball, Simon; Bew, Carolyn; Bloxham, Sue; Brown, Sally; Kleiman, Paul; May, Helen; McDowell, Liz; Morris, Erica; Payne, Elaine; Price, Margaret; Rust, Chris; Smith, Brenda and Waterfield, Judith (2012). A Marked Improvement: transforming assessment in higher education, The Higher Education Academy. https:// www.heacademy.ac.uk/knowledge-hub/marked-improvement

Oswald, Karl M. and Rhoten, Stephanie E. (2014). Improving classroom clicker practices: effects of incentives and feedback on retention. North American Journal of Psychology, 16 (1), 79-88.

Race, Philip (2014). Making learning happen: a guide for post-compulsory education. 3rd ed. (Chapter 4: Assessment driving learning), Sage publications.

Rust, Chris (2001). Basic assessment issues and terminology, Assessment in Higher Education. https:// assessmentinhe.files.wordpress.com/2015/04/rust_assessment_terminology.pdf

Rust, Chris (2002). The impact of assessment on student learning: how can the research literature practically help to inform the development of departmental assessment strategies and learner-centred assessment practices?" Active Learning in Higher Education. 3(2), 145-158.

Ryan, Tracii; Henderson, Michael and Phillips, Michael (2019). Feedback modes matter: Comparing student perceptions of digital and non-digital feedback modes in higher education. British Journal of Educational Technology. 50(3), 1507-1523.

Trumbore, Anne (2014). Rules of engagement: strategies to increase online engagement at scale change. The Magazine of Higher Learning. 46(4), 38-45.

Tynan, Belinda; Ryan, Yoni; Lamont-Mills, Andrea (2015). Examining workload models in online and blended teaching". British Journal of Educational Technology. 46(1), 5-15.

Yorke, Mantz (2001). Formative assessment and its relevance to retention". Higher Education Research and Development. 20(2), 115-126.

Cite this article as: Salwa M ohamed and Fiona Long (2021). A ssessment and feed back strategies that foster students' engagement in thelanguage classroom. International J ournal of Education and Teaching. 1(1), 13-18. doi: 10.51483/ IJEDT.1.1.2021.13-18. 